NBER WORKING PAPER SERIES

\title{
MEASURING OPENNESS TO TRADE
}

Michael E. Waugh

B. Ravikumar

Working Paper 22147

http://www.nber.org/papers/w22147

\author{
NATIONAL BUREAU OF ECONOMIC RESEARCH \\ 1050 Massachusetts Avenue \\ Cambridge, MA 02138 \\ April 2016
}

We thank Raphael Auer, Mario Crucini, Harris Dellas, Jonathan Eaton, Ray Riezman, and the participants at the 2015 Conference on International Economics at the Study Center in Gerzensee for useful comments. The views expressed in this article are those of the authors and do not necessarily reflect the views of the Federal Reserve Bank of St. Louis, the Board of Governors, the Federal Reserve System, or the National Bureau of Economic Research.

NBER working papers are circulated for discussion and comment purposes. They have not been peer-reviewed or been subject to the review by the NBER Board of Directors that accompanies official NBER publications.

(C) 2016 by Michael E. Waugh and B. Ravikumar. All rights reserved. Short sections of text, not to exceed two paragraphs, may be quoted without explicit permission provided that full credit, including (C) notice, is given to the source. 
Measuring Openness to Trade

Michael E. Waugh and B. Ravikumar

NBER Working Paper No. 22147

April 2016, Revised July 2016

JEL No. E1,F11,F40,F62,F63

\begin{abstract}
$\underline{\text { ABSTRACT }}$
In this paper we derive a new measure of openness-trade potential index-that quantifies potential gains from trade as a simple function of data. Using a standard multicountry trade model, we measure openness by a country's potential welfare gain from moving to a world with frictionless trade. In this model, a country's trade potential depends on only the trade elasticity and two observable statistics: the country's home trade share and its income level. Quantitatively, poor countries have greater potential gains from trade relative to rich countries, while their welfare costs of autarky are similar. This leads us to infer that rich countries are more open to trade. Our trade potential index correlates strongly with estimates of trade costs, while both the welfare cost of autarky and the volume of trade correlate weakly with trade costs. Thus, our measure of openness is informative about the underlying trade frictions.
\end{abstract}

\author{
Michael E. Waugh \\ Stern School of Business \\ New York University \\ 44 West Fourth Street, Suite 7-160 \\ New York, NY 10012 \\ and NBER \\ mwaugh@stern.nyu.edu \\ B. Ravikumar \\ Research Division \\ Federal Reserve Bank of St. Louis \\ P.O. Box 442 \\ St. Louis, MO 63166-0442 \\ b.ravikumar@wustl.edu
}




\section{Introduction}

How open is a country to trade? And, how large are the welfare gains from trade? These questions typically have been answered by computing the welfare cost of autarky-the change in real income due to a change from the observed equilibrium to autarky. Arkolakis, Costinot, and Rodriguez-Clare (2012) show that this calculation in a large class of models takes a simple form: a country's home trade share raised to the power of the inverse of the trade elasticity. ${ }^{1}$

In this paper, we deliver a measure of openness that quantifies the potential gains from trade. Our "trade potential" measures how much each country can gain by moving from a current world with trade costs to a frictionless world. We define a country's trade potential as the change in real income per worker due to a change from the observed equilibrium to the frictionless trade equilibrium. Within a standard model of trade, we show that a country's trade potential takes a simple form: It is proportional to

$$
\left(\frac{\lambda_{i i}}{Y_{i}}\right)^{\frac{1}{1+\theta}},
$$

where $\lambda_{i i}$ is country $i$ 's observed home trade share, $Y_{i}$ is country $i$ 's observed real gross domestic product (GDP), and $\theta$ is the trade elasticity. ${ }^{2}$ Relative to the standard welfare cost of autarky calculation, the key feature of our measure is that it encodes how a country's potential depends on its technology and endowments as summarized by its observed GDP. This distinction is important because two countries may have the same welfare cost of autarky but vastly different potentials. Empirically, this is the pattern in the data. We show that the welfare cost of autarky is similar across countries, but poor countries have greater potential gains from trade.

We derive our measure by embedding the multicountry trade model developed by Eaton and Kortum (2002) (hereafter EK) into a neoclassical growth model. Each country is endowed with a stock of capital and a labor force. Both factors are immobile across countries. There is a continuum of tradable goods. The distribution of productivity over the continuum belongs to the Fréchet family; countries differ in the centering parameter but have a common shape parameter. International trade is subject to barriers in the form of iceberg trade costs. All markets are competitive. The amount of trade between any two countries, in equilibrium, depends on technologies and trade costs.

Operationally, measuring trade potential requires computing the change in real GDP per worker from its current observed level to a new level in the frictionless world. To compute the change,

\footnotetext{
${ }^{1} \mathrm{~A}$ country's home trade share is 1 minus the fraction of the country's expenditures on goods from all other countries.

${ }^{2}$ The constant of proportionality is a cross-country-weighted average of the expression in (1), is not country specific, and ensures that the trade potential is unit free.
} 
we proceed in three steps. We first provide a closed-form expression for a country's real GDP per worker, regardless of the trade costs. This expression depends on the country's home trade share, technology parameter, labor and capital endowments, and two non-country-specific parameters - the trade elasticity and capital's share in production. This expression shows how a country with a larger technology parameter or capital endowment per worker will be relatively richer. We can use this expression for real GDP per worker in the frictionless world, but each country's home trade share in the frictionless world requires knowledge of the country-specific technology parameters.

In the second step, we measure the country-specific technology parameters. With the closedform expression from the first step, we derive each country's technology parameter as a simple function of three observables for the country-real GDP per worker, capital per worker, and the home trade share. Our measurement of the technology parameter is similar to the measurement of total factor productivity (TFP) in the development accounting literature (see, for instance, Hall and Jones (1999), Caselli (2005)).

In the third step, we note that each country's home trade share in the frictionless world is equal to the country's share in world GDP in the frictionless world. Knowing the technology parameter from the second step and the closed-form expression from the first step, we determine each country's GDP in the frictionless world as a function of observables and infer the country's trade potential.

Our approach yields the surprising result that a country's trade potential is completely summarized by its observed home trade share and GDP, as shown in (1). Details such as its capital stock, labor endowment, technology, and so on are not necessary to calculate the trade potential.

The important qualitative prediction of our measure of openness is how a country's trade potential depends on its current level of income. As (1) makes clear, holding all else constant, a country whose observed real GDP is relatively low has relatively more to gain from trade. In other words, the poorest countries have the highest potential gains from trade.

This prediction highlights our contribution relative to measures of openness based on the standard welfare cost of autarky. The welfare cost of autarky calculation implies that if a rich country and a poor country have the same home trade share, then both countries experience the same loss from a move to autarky - that is, the welfare cost is the same across countries. Missing from this inference, however, is the possibility that the poor country could have more to gain from trade- that is, a greater trade potential. Put differently, the observed equilibrium for a poor country might be close to autarky but far from frictionless trade, while the observed equilibrium for a rich country might be close to autarky but also close to frictionless trade. If poor countries indeed have greater trade potentials we infer that they are more closed relative to rich countries. 
Table 1: Top 10 Most Open Countries

\begin{tabular}{lll}
\hline \hline \multicolumn{1}{c}{ Imports/GDP } & \multicolumn{1}{c}{ Welfare Cost of Autarky } & Trade Potential Index \\
Luxembourg* & Luxembourg* & Luxembourg* $^{*}$ \\
Antigua and Barbuda & Antigua and Barbuda & Netherlands* \\
Estonia* & Estonia* & Germany \\
Malta & Malta & Estonia* \\
Iceland & Iceland & Hungary \\
Suriname & Suriname & Austria \\
Fiji & Fiji & Switzerland \\
Netherlands* & Netherlands* & United States \\
Jamaica & Jamaica & Denmark \\
St. Vincent and the Grenadines & St. Vincent and the Grenadines & United Kingdom \\
\hline
\end{tabular}

Note: Asterisks indicate a country appears in both lists.

We quantify our measure of openness using data on trade shares, endowments, and GDP directly from the Penn World Tables (PWT). We find two important results. First, poor countries have greater trade potential relative to rich countries, while the welfare cost of autarky of poor countries is similar to that of rich countries. The feature of the data delivering this pattern is that home trade shares do not vary strongly with the level of GDP. This observation and our simple formula in (1) immediately imply greater trade potential for poor countries.

An implication of this result is that relative to their potential, rich countries are more open. We formalize this by constructing a trade potential index that maps each country's observed position into the $0-1$ interval, with 0 being autarky and 1 being frictionless trade. Because poor countries have greater trade potential, they are closer to autarky relative to rich countries. Table 1 illustrates this. The U.S., the U.K., and Germany are not in the top 10 list of open countries when openness is measured by the welfare cost of autarky (or by the volume of trade such as the imports-to-GDP ratio), but they are in the top 10 according to our trade potential index.

Second, our trade potential index correlates strongly with estimates of trade costs, unlike the welfare cost of autarky (or the aggregate volume of trade). We show this result in two ways. One, we calibrate the trade costs in our model to deliver the observed home trade share and observed distribution of income. The correlation between these trade costs and our trade potential index is -0.94 . Even after conditioning on income level, this correlation remains high at -0.88 . In contrast, the correlation between these trade costs and the welfare costs of autarky, conditional on income, is only -0.28 . Two, we compare our measure of openness with trade costs estimated using a gravity equation, as in Simonovska and Waugh (2014). The correlation is -0.75 . Since the trade costs in Simonovska and Waugh (2014) are neither calibrated using our model nor estimated using our data, the high correlation strongly suggests that the simple 
statistic in (1) is indeed a good measure of openness.

\section{Model}

We outline the environment of the multicountry Ricardian model of trade introduced by EK. We consider a world with $N$ countries, where each country has a tradable final-goods sector. There is a continuum of tradable goods indexed by $j \in[0,1]$.

Within each country $i$, there is a representative consumer of size $L_{i}$. This consumer supplies labor inelastically in the domestic labor market and also owns physical capital $K_{i}$, which is inelastically supplied to the domestic capital market. This consumer also enjoys the consumption of a CES bundle of final tradable goods with elasticity of substitution $\rho>1$ :

$$
U_{i}=\left[\int_{0}^{1} x_{i}(j)^{\frac{\rho-1}{\rho}} d j\right]^{\frac{\rho}{\rho-1}} .
$$

To produce quantity $x_{i}(j)$ in country $i$, a firm employs a Cobb-Douglas production function combining capital and labor with factor shares $\alpha$ and $1-\alpha$ and productivity $z_{i}(j)$. Country $i^{\prime}$ s productivity for good $j$ is, in turn, the realization of a random variable (drawn independently for each good $j$ ) from its country-specific Fréchet probability distribution:

$$
F_{i}\left(z_{i}\right)=\exp \left(-T_{i} z_{i}^{-\theta}\right)
$$

The country-specific parameter $T_{i}>0$ governs the location of the distribution; higher values of it imply that a high productivity draw for any good $j$ is more likely. The parameter $\theta>1$ is common across countries and, if higher, generates less variability in productivity across goods in each country.

Having drawn a particular productivity level, a perfectly competitive firm from country $i$ incurs a marginal cost of $r_{i}^{\alpha} w_{i}^{1-\alpha} / z_{i}(j)$ to produce good $j$, where $w_{i}$ is the wage rate and $r_{i}$ is the rental rate of capital in country $i$. Shipping the good to destination $n$ requires a per-unit iceberg trade cost of $\tau_{n i}>1$ for $n \neq i$, with $\tau_{i i}=1$. We assume that cross-border arbitrage forces effective geographic barriers to obey the triangle inequality: For any three countries, $i, k, n$, $\tau_{n i} \leq \tau_{n k} \tau_{k i}$.

Below, we describe equilibrium prices, trade flows, real GDP per worker, and the welfare cost of autarky.

Prices. Perfect competition implies that the price of good $j$ from country $i$ to destination $n$, 
$p_{n i}(j)$, is equal to the marginal cost of production and delivery:

$$
p_{n i}(j)=\frac{\tau_{n i} r_{i}^{\alpha} w_{i}^{1-\alpha}}{z_{i}(j)}
$$

So, consumers in destination $n$ would pay $p_{n i}(j)$, should they decide to buy good $j$ from $i$. Consumers purchase good $j$ from the least-cost supplier; thus, the actual price consumers in $n$ pay for good $j$ is the minimum price across all sources $\ell$ :

$$
p_{n}(j)=\min _{\ell=1, \ldots, N}\left\{p_{n \ell}(j)\right\} .
$$

The pricing rule and the productivity distribution allow us to obtain the following CES exact price index, $P_{n}$, for each destination $n$ :

$$
P_{n}=\gamma \Phi_{n}^{-\frac{1}{\theta}}, \quad \text { where } \quad \Phi_{n}=\left[\sum_{\ell=1}^{N} T_{\ell}\left(\tau_{n \ell} r_{\ell}^{\alpha} w_{\ell}^{1-\alpha}\right)^{-\theta}\right] .
$$

In the above equation, $\gamma=\left[\Gamma\left(\frac{\theta+1-\rho}{\theta}\right)\right]^{\frac{1}{1-\rho}}$ is the gamma function, and parameters are restricted such that $\theta>\rho-1$.

Trade Flows. To calculate trade flows between countries, let $X_{n}$ be country $n$ 's expenditure on tradable goods, of which $X_{n i}$ is spent on goods from country $i$. Since there is a continuum of goods, the fraction of income spent on imports from $i, X_{n i} / X_{n}$, can be shown to be equivalent to the probability that country $i$ is the least-cost supplier to country $n$ given the joint distribution of productivity levels, prices, and trade costs for any good $j$. In the equations below, we do not include proportionality constants that are not country specific since such constants will not enter into our welfare gain calculations or our measure of openness.

The expression for the share of expenditures that $n$ spends on goods from $i$ or, as we call it, the trade share, $\lambda_{n i}$, is

$$
\lambda_{n i}:=\frac{X_{n i}}{X_{n}}=\frac{T_{i}\left(\tau_{n i} r_{i}^{\alpha} w_{i}^{1-\alpha}\right)^{-\theta}}{\sum_{\ell=1}^{N} T_{\ell}\left(\tau_{n k} r_{\ell}^{\alpha} w_{\ell}^{1-\alpha}\right)^{-\theta}} .
$$

Expressions (6) and (7) allow us to relate trade shares to trade costs and the price indices of each trading partner by the following equation:

$$
\frac{\lambda_{n i}}{\lambda_{i i}}=\left(\frac{P_{i} \tau_{n i}}{P_{n}}\right)^{-\theta}
$$

where $\lambda_{i i}$ is country $i$ 's expenditure share on goods from country $i$, or its home trade share. 
While well known, it is worth reiterating that expression (8) is not particular to EK's model. Several popular models of international trade relate trade shares, prices, and trade costs in the same manner. These models include Anderson (1979); Krugman (1980); Bernard, Eaton, Jensen, and Kortum (2003); and Melitz (2003) when parameterized as in Chaney (2008).

Real GDP per Worker. A feature of this model (and other trade models) is that real GDP per worker can be expressed in a form similar to that in a standard one-sector growth model. The expression in trade models and in the one-sector growth model contains a TFP term and a capital-labor ratio raised to a power term. The key difference is that measured TFP in trade models is endogenous and depends on the country's home trade share.

To arrive at this representation of GDP per worker, a couple of steps are needed. First, with competitive factor markets, the rental rate on capital is pinned down by the following relationship: $r_{i}=\frac{\alpha}{1-\alpha} w_{i} k_{i}^{-1}$, where $k$ is the aggregate capital-labor ratio. Second, combining this relationship with (7) yields an expression for each country's home trade share:

$$
\lambda_{i i}=\frac{\left[k_{i}^{-\alpha} w_{i}\right]^{-\theta} T_{i}}{\sum_{\ell=1}^{N} T_{\ell}\left(\tau_{i \ell} k_{\ell}^{-\alpha} w_{\ell}\right)^{-\theta}} .
$$

Third, using (6) and a rearrangement of (9) provides an expression for the real wage:

$$
\frac{w_{i}}{P_{i}}=(1-\alpha) T_{i}^{\frac{1}{\theta}} \lambda_{i i}^{\frac{-1}{\theta}} k_{i}^{\alpha},
$$

in which wages, deflated by the aggregate price index, are a function of each country's technology parameter, its home trade share, and its capital-labor ratio. ${ }^{3}$

Finally, using balanced trade and equating production of the aggregate commodity with total factor payments, we get

$$
y_{i}=\frac{w_{i}}{P_{i}}+\frac{r_{i} k_{i}}{P_{i}} .
$$

Then, using (10) and the observation above that the wage-rental ratio is proportional to the capital-labor ratio gives

$$
y_{i}=A_{i} k_{i}^{\alpha}, \quad \text { where } \quad A_{i}=T_{i}^{\frac{1}{\theta}} \lambda_{i i}^{\frac{-1}{\theta}} .
$$

Real GDP per worker in the model is expressed in the same way as in the standard one-sector growth model. The key difference is that measured TFP in (12) contains an endogenous trade

\footnotetext{
${ }^{3}$ Other than the role of capital, (10) is the same expression discussed extensively in Arkolakis, Costinot, and Rodriguez-Clare (2012) that relates home trade shares and the real wage.
} 
factor, $\lambda_{i i}^{\frac{-1}{\theta}}$, and an exogenous domestic factor, $T_{i}^{\frac{1}{\theta}} \cdot{ }^{4}$

Several comments are in order regarding (12). First, the balanced trade assumption may seem strong, but it is not. A similar expression, but with an additive term representing trade imbalance, is easily derivable. We abstract from trade imbalances this paper.

Second, since the expressions for trade shares are not specific to the EK model, there is nothing unique about (12) and its association with the EK model. Many trade models share the same "gravity equation" (i.e., equation 7), so inverting the home trade share (as we did from (9) to (10)) delivers the same expression for the real wage irrespective of the micro details of trade. In some ways, this observation is the essence of the isomorphism result in Arkolakis, Costinot, and Rodriguez-Clare (2012).

Third, the expression in (12) is closely connected to the use of the one-sector growth model in (closed-economy) accounting exercises such as those of Hall and Jones (1999) and Caselli (2005) to measure TFP. This connection provides a method to identify a country's technology parameter. Identifying a country's technology parameter is important because, as we will show later, the set of technology parameters and observed endowments are sufficient to completely characterize the cross-country distribution of income per worker in the frictionless economy.

Welfare Cost of Autarky. Given the representation of real GDP per worker in (12), it is straightforward to compute the change in real income due to a change from an observed equilibrium to autarky (i.e., the welfare cost of autarky). In autarky, country $i$ purchases all goods from itself, implying that $\lambda_{i i}=1$. Since technology and endowments are fixed, the change in real income from an observed equilibrium $y$ to autarky $y^{A U}$ is

$$
\frac{y_{i}^{A U}}{y_{i}}=\lambda_{i i}^{\frac{1}{\theta}}
$$

which is the same formula derived in Arkolakis, Costinot, and Rodriguez-Clare (2012).

The power of (13) is its simplicity. Give a researcher two statistics-the home trade share and the trade elasticity-and he can compute the welfare cost of autarky. The weakness is that countries with the same home trade shares are considered identical. That is, conditional on an observed level of trade, the distance in welfare terms is the same for all countries, regardless of the other differences between them. If the home trade shares look similar across countries, then a natural inference on openness based on (13) would be that rich and poor countries are similar. For instance, the home trade share for the U.S. is 0.81 and that for Malawi is 0.80 , so a measure of openness using the welfare cost in (13) would rank the U.S. and Malawi similarly. Missing from this inference is the role of technology and endowments in determining a coun-

\footnotetext{
${ }^{4}$ This "openness-adjusted" measure of TFP has been noted previously in Waugh (2010) and in Finicelli, Pagano, and Sbracia (2013).
} 
try's possibilities. That is, a country's "distance to the frictionless frontier" will differ depending on its technology and endowments, even after conditioning on an observed level of trade. Understanding these possibilities is important because while two countries may have the same welfare cost of autarky, one may be more or less closed compared with its potential.

The next section derives a measure of openness—trade potential—and shows how to compute it using easily available data.

\section{Trade Potential}

In this section, we first derive an expression for each country's income level in the frictionless trade economy as a function of the unobservable technology parameters. We then combine (12) with observables to infer the technology parameters. This allows us to measure each country's trade potential as a function of observables. Finally, we derive a trade potential index that maps the observed equilibrium of a country to a point between autarky and the frictionless trade equilibrium.

A few observations allow us to compute a country's income level in frictionless trade. First, in frictionless trade, prices across countries are the same, so a country's home trade share equals the share of its real GDP in world real GDP. Country $i$ 's home trade share is

$$
\lambda_{i i}^{F T}=\frac{L_{i} y_{i}^{\mathrm{FT}}}{\sum_{\ell=1}^{N} L_{\ell} y_{\ell}^{\mathrm{FT}}},
$$

where $y_{i}^{\mathrm{FT}}$ is a country's real GDP per worker in frictionless trade. Second, combining (14) with the general representation of real GDP per worker in (12) allows us solve for a country's income level in frictionless trade. Appendix A provides a detailed derivation; Proposition 1 summarizes this result.

Proposition 1 (GDP per Worker in a Frictionless Economy) Real GDP per worker in the frictionless trade economy, $y_{i}^{F T}$, is

$$
y_{i}^{F T}=\Omega(\mathbf{L}, \mathbf{T}, \mathbf{k})\left(\frac{T_{i}}{L_{i}}\right)^{\frac{1}{1+\theta}} k_{i}^{\frac{\alpha \theta}{1+\theta}},
$$

where

$$
\Omega(\mathbf{L}, \mathbf{T}, \mathbf{k})=\left(\sum_{\ell=1}^{N} L_{\ell}\left(\frac{T_{\ell}}{L_{\ell}}\right)^{\frac{1}{1+\theta}} k_{\ell}^{\frac{\alpha \theta}{1+\theta}}\right)^{\frac{1}{\theta}} .
$$

(Each bold letter describes the vector of the relevant variable for all countries.) 
Proposition 1 states that a country with a larger technology parameter or capital endowment will have larger GDP per worker in a frictionless economy. This is intuitive: A country's position in the distribution of income will reflect its advantages in technology or capital. ${ }^{5}$

The $\Omega$ term in (16) summarizes the effects of all other countries on the income level of a country. It is essentially a weighted sum of each country's income term in (15). Because $\Omega$ is common to all countries, it does not affect a country's relative position in the cross-country distribution of income-it simply scales all incomes up or down.

Finally, a country's potential income level is measurable from readily available data (e.g., the PWT). Equation (12) provides estimates of a country's technology parameter. Specifically, we measure the technology parameter $T$ as

$$
T_{i}=\left(y_{i} k_{i}^{-\alpha}\right)^{\theta} \lambda_{i i} .
$$

The term in the first set of brackets is the standard "Solow residual." Take the Solow residual to the power of the trade elasticity $\theta$ and scale it by a country's home trade share and one has a measure of a country's technology parameter. Substitution of (17) into (15) provides a country's income level in a frictionless world as a function of data. The potential change in real income a country could experience from moving to the frictionless trade economy-trade potentialdirectly follows from this expression. Proposition 2 summarizes this result.

Proposition 2 (Trade Potential) A country's GDP per worker in the frictionless trade economy is

$$
y_{i}^{F T}=\tilde{\Omega}(\mathbf{Y}, \lambda)\left(\frac{\lambda_{i i}}{Y_{i}}\right)^{\frac{1}{1+\theta}} y_{i}
$$

with

$$
\tilde{\Omega}(\mathbf{Y}, \lambda)=\left(\sum_{\ell=1}^{N} Y_{\ell}\left(\frac{\lambda_{\ell \ell}}{Y_{\ell}}\right)^{\frac{1}{1+\theta}}\right)^{\frac{1}{\theta}} .
$$

The change in real income from a country's observed income to that in the frictionless trade economy is

$$
\frac{y_{i}^{F T}}{y_{i}}=\tilde{\Omega}(\mathbf{Y}, \lambda)\left(\frac{\lambda_{i i}}{Y_{i}}\right)^{\frac{1}{1+\theta}} .
$$

Equation (18) expresses a country's income level in the frictionless economy as a function of its

\footnotetext{
${ }^{5}$ Equations (15) and (16) are closely related to equation (23) in Eaton and Kortum (2002). The key distinctions are that we (i) abstract from an input-output relationship among intermediates and (ii) include capital. These distinctions are not crucial for our purpose since our main contribution is to compute each country's income in a frictionless trade economy even though each country's technology parameter is unobservable.
} 
current home trade share, total GDP, and GDP per worker. A richer country with less trade will have a higher income level in the frictionless trade economy.

The $\tilde{\Omega}$ term is (essentially) a GDP-weighted sum of each country's term $\left(\frac{\lambda_{i i}}{Y_{i}}\right)^{\frac{1}{1+\theta}}$. This ensures that the trade potential in (20) is unit free.

An interesting feature of (18) is that capital and labor endowments do not appear in the equation; only the home trade share and GDP matter. This indicates that the reason a country is rich or poor does not matter; what matters is simply that it is rich or poor. The importance of a country's endowments for computing its trade potential is completely summarized by its current income level.

Current income acts as a summary statistic in (18) partly because the factors of production, capital and labor, are assumed to remain the same as the economy moves from the observed equilibrium to the frictionless trade equilibrium. If capital is accumulated as the economy moves to the frictionless trade equilibrium, as in Mutreja, Ravikumar, and Sposi (2014), then income in the frictionless trade equilibrium would include the effect of the change in capital stock in addition to the change in the home trade share.

Equation (20) provides a welfare metric regarding how far a country is from the frictionless frontier as a function of observables. The key insight from (20) is the influence of the current income level on a country's distance to the frontier. Holding fixed the volume of trade, the poorer a country is, the greater its trade potential. Thus, two countries with the same home trade shares are not considered identical in our measure of openness, unlike measures of openness based on the welfare cost of autarky.

\subsection{Trade Potential Index}

Using our openness measure (20) and the welfare cost of autarky in (13), we construct a statistic $\Lambda_{i}$ that summarizes a country's position between autarky and frictionless trade. Proposition 3 summarizes the result.

Proposition 3 (Trade Potential Index) A country's position between autarky and frictionless trade is summarized by

$$
\Lambda_{i}=\frac{1-\lambda_{i i}^{1 / \theta}}{\tilde{\Omega}(\mathbf{Y}, \lambda)\left(\frac{\lambda_{i i}}{Y_{i}}\right)^{\frac{1}{1+\theta}}-\lambda_{i i}^{1 / \theta}}
$$

where this statistic has the following properties: (i) it lies between 0 and 1, (ii) equals 0 in autarky, and (iii) equals 1 in frictionless trade.

The trade potential index in Proposition 3 is useful for putting into perspective the relative 
magnitudes of the welfare cost of autarky in (13) and the trade potential in (20). Our statistic in (21) places a country's welfare cost of autarky in the context of its trade potential. While a country may have a relatively high welfare cost of autarky, it may still be far from frictionless trade. Conversely, a country might be close to autarky but also close to frictionless trade.

\section{Quantifying Trade Potential}

The key feature of (20) and (21) is that the only data required to compute a country's trade potential and its trade potential index are its GDP and home trade share and the estimate of trade elasticity. Below we discuss the country-specific data and the trade elasticity that we use.

\subsection{Cross-Country Data and Trade Elasticity}

Output per worker and the number of workers are standard measures used in development and growth accounting exercises. In our computations, we use the expenditure side of the output measure because this measure of real GDP treats trade balances in the same way as we treat them in the model-that is, exports and imports are deflated together and not separately as in production-side measures of GDP. See, for example, Feenstra, Heston, Timmer, and Deng (2004) and Waugh (2010) for a more detailed explanation.

We measure a country's home trade share, $\lambda_{i i}$, as 1 minus a country's ratio of imports to GDP at current prices. An issue with our measure of home trade share is that imports are largely intermediates and measured in gross terms, while GDP is a value added measure. One approach to correct this mismatch is to "gross up" GDP by a multiplier that represents the intermediates' share in value added. If this multiplier is constant across countries, the quantitative effect would be on the level of potential gains for each country and not on the relative gain of the country in the cross-country distribution of gains. Another alternative would be to explicitly model intermediates directly as in EK, Alvarez and Lucas (2007), or Waugh (2010) and construct measures of home trade shares using gross production rather than value added. Measures of home trade shares using gross production would affect the level of gains and the relative gain in the cross-country distribution only if the differences in measures of home trade shares varied systematically across countries.

We focus on the year 2005, which is the the benchmark year for the PWT 8.1. We exclude any countries with missing data. We also exclude the few countries with an imports-to-GDP ratio larger than 1 (e.g., Belgium, Panama). This leaves 160 countries in the sample.

As a baseline we set $\theta$ equal to 4 . This is consistent with the estimates from Simonovska and Waugh (2014), who provide an extensive discussion on other estimates from the literature. A short summary is that a variety of different methods and estimation procedures point to a 


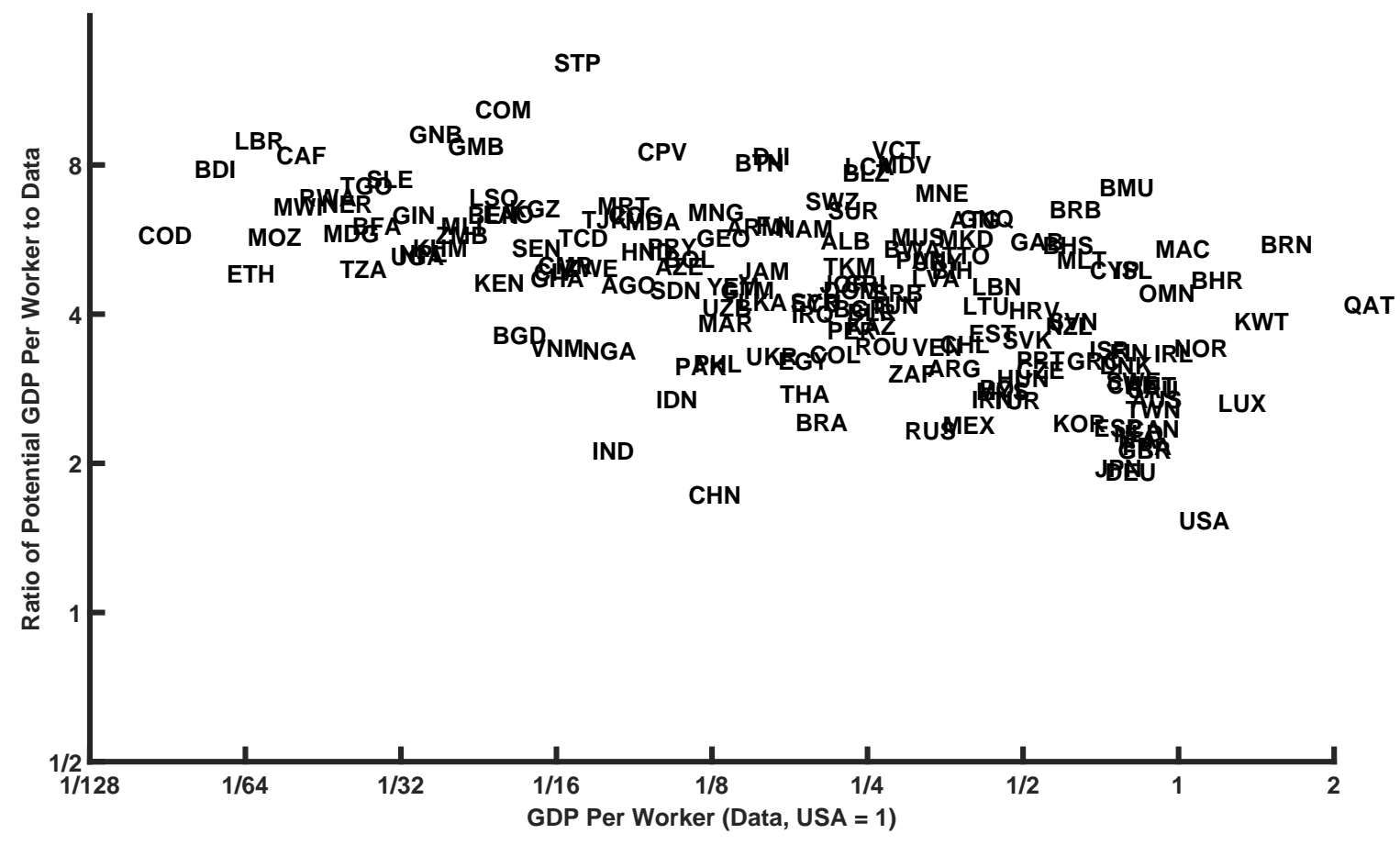

(a) Trade Potential Versus GDP Per Worker

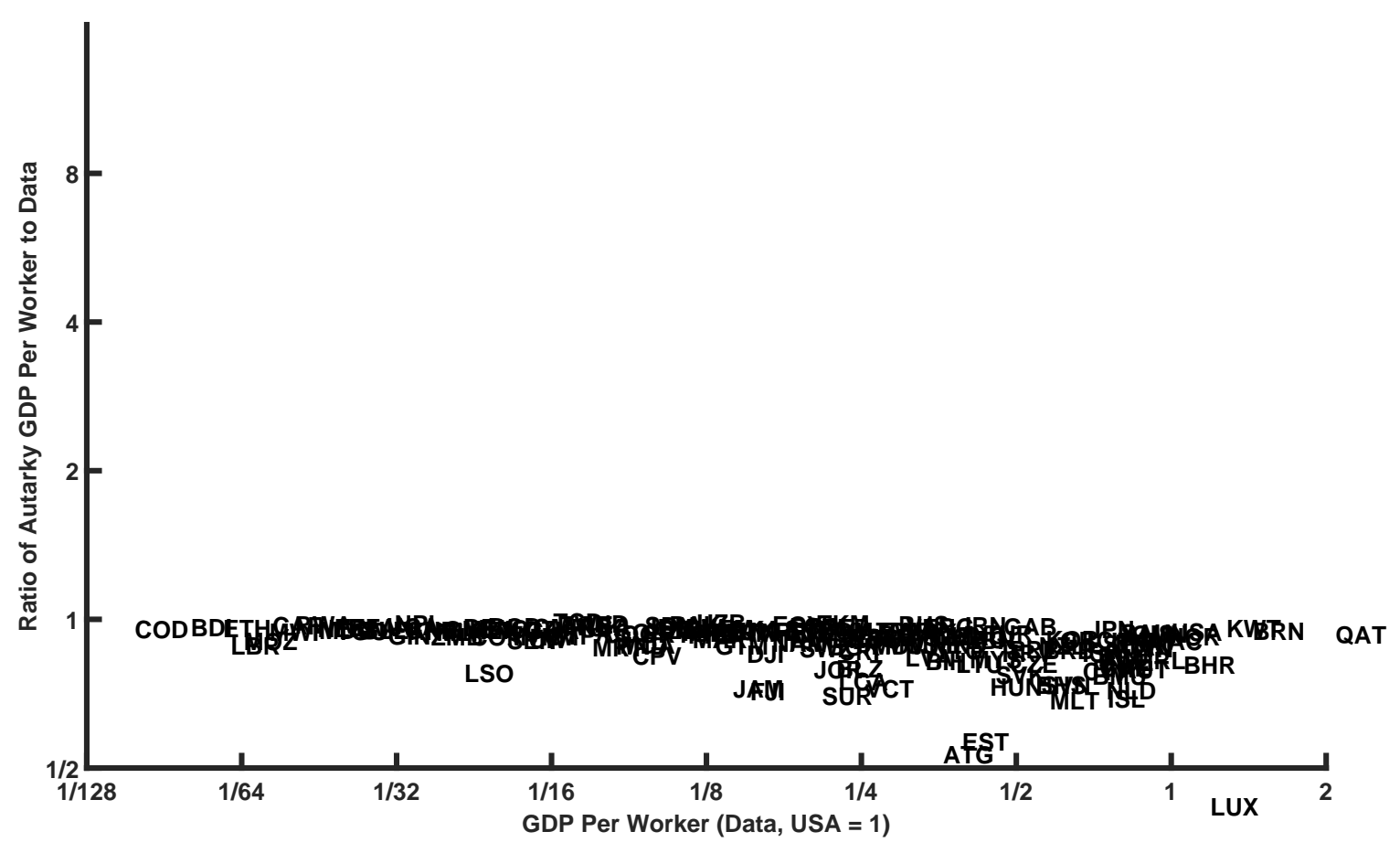

(b) Autarky Versus GDP Per Worker

Figure 1: GDP Per Worker: Potential and Autarky Versus Data 
plausible range of $\theta$ between 3 and 5 .

\subsection{Trade Potential}

Figure 1(a) plots the trade potential versus the logarithm of observed GDP per worker. Below we make several observations.

First, the trade potential for each country is large-the average across countries is almost 4 . For the median country in the observed income distribution, the trade potential is 5 .

These potentials are larger than the gains reported in EK for their sample of 19 OECD countries. The difference is mainly due to the size of our sample (160 countries) and the trade elasticity we use. Note that the $\tilde{\Omega}$ term in (20) is a GDP weighted sum, so as we add more countries, trade potential increases. If we compute our trade potential using only the 19 countries in EK, the average trade potential decreases to 2. If we use EK's estimate of 8.28 for the trade elasticity, then the average trade potential is only 1.4. Together, these two differences account for most of the differences between our gains and those in EK.

Second, as shown in Figure 1(a), there is a negative relationship between trade potential and economic development. Poor countries have substantially higher potential than rich countries. The trade potential for Malawi is five times that of the U.S.

Our third observation is that the losses from autarky are minimal (as in Arkolakis, Costinot, and Rodriguez-Clare (2012)). For example, the welfare cost of autarky for the median country in the observed income distribution is only 0.98 , which implies that the GDP per worker in autarky is almost the same as the observed GDP per worker for the median country (see equation (13)). Figure 1(b) provides a comparison with the trade potentials in Figure 1(a). The vertical axis in Figure 1(b) plots each country's autarky GDP relative to its observed GDP, per worker. The welfare costs are tiny compared with the trade potential in Figure 1(a). This observation suggests that relative to the potential gains from moving to frictionless trade, the observed world is close to autarky. Our trade potential index in (21) quantifies this observation.

\subsection{Trade Potential Index}

Recall that our trade potential index maps each country's observed position as a value between 0 and 1 . If a country's value is near 1, then the country is close to the frictionless trade frontier; if a country's value is near 0 , then it is close to autarky.

Figures 2(a) and 2(b) both plot the trade potential index but on different scales; Figure 2(a) plots the index over the entire range 0 to 1 and Figure 2(b) zooms in.

Figure 2(a) shows the world is essentially in autarky. The values for many countries lie near 0 with notable exceptions (Germany and the Netherlands). The average trade potential index is 


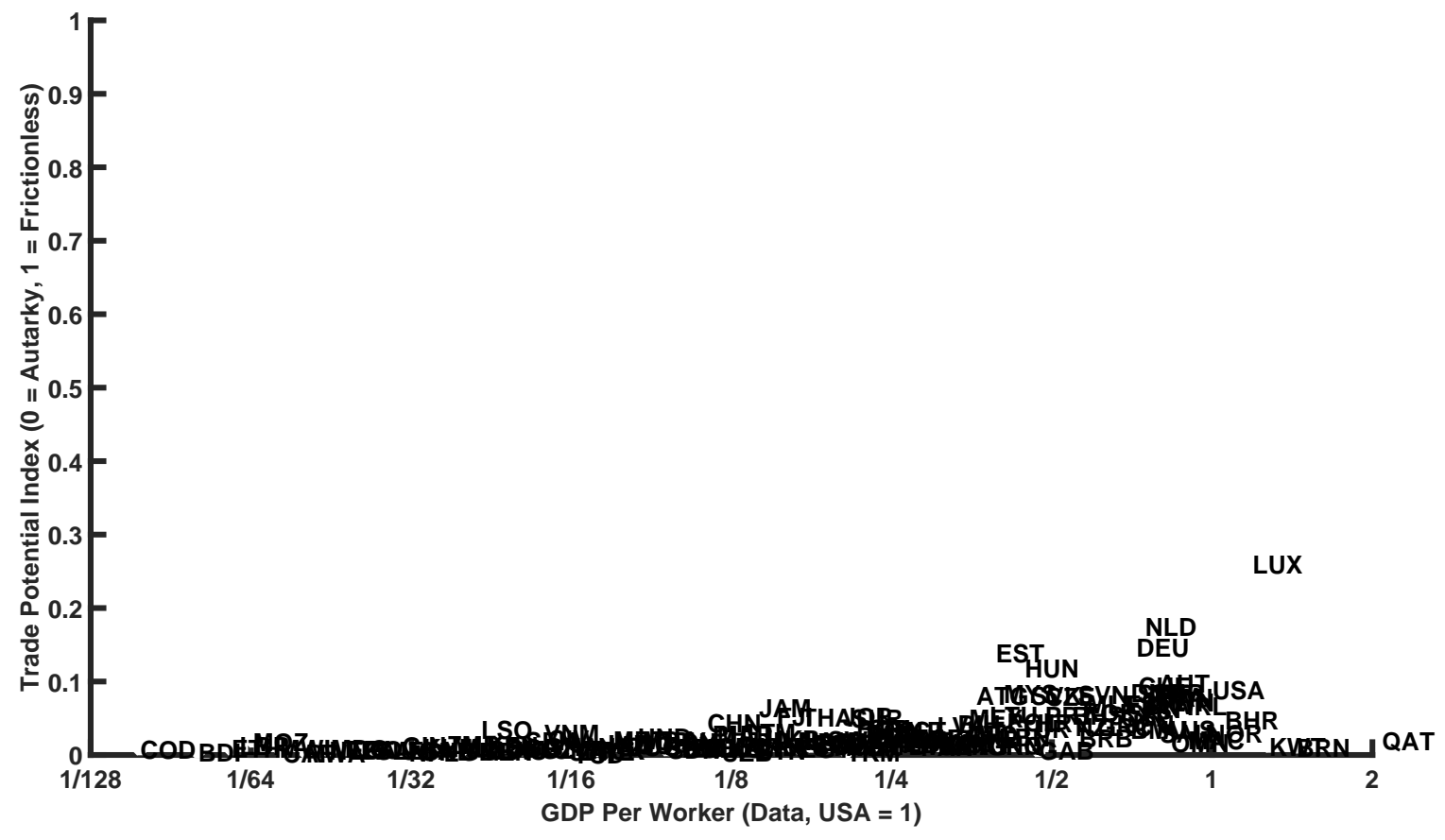

(a) Trade Potential Index $\Lambda_{i}$ Versus GDP Per Worker

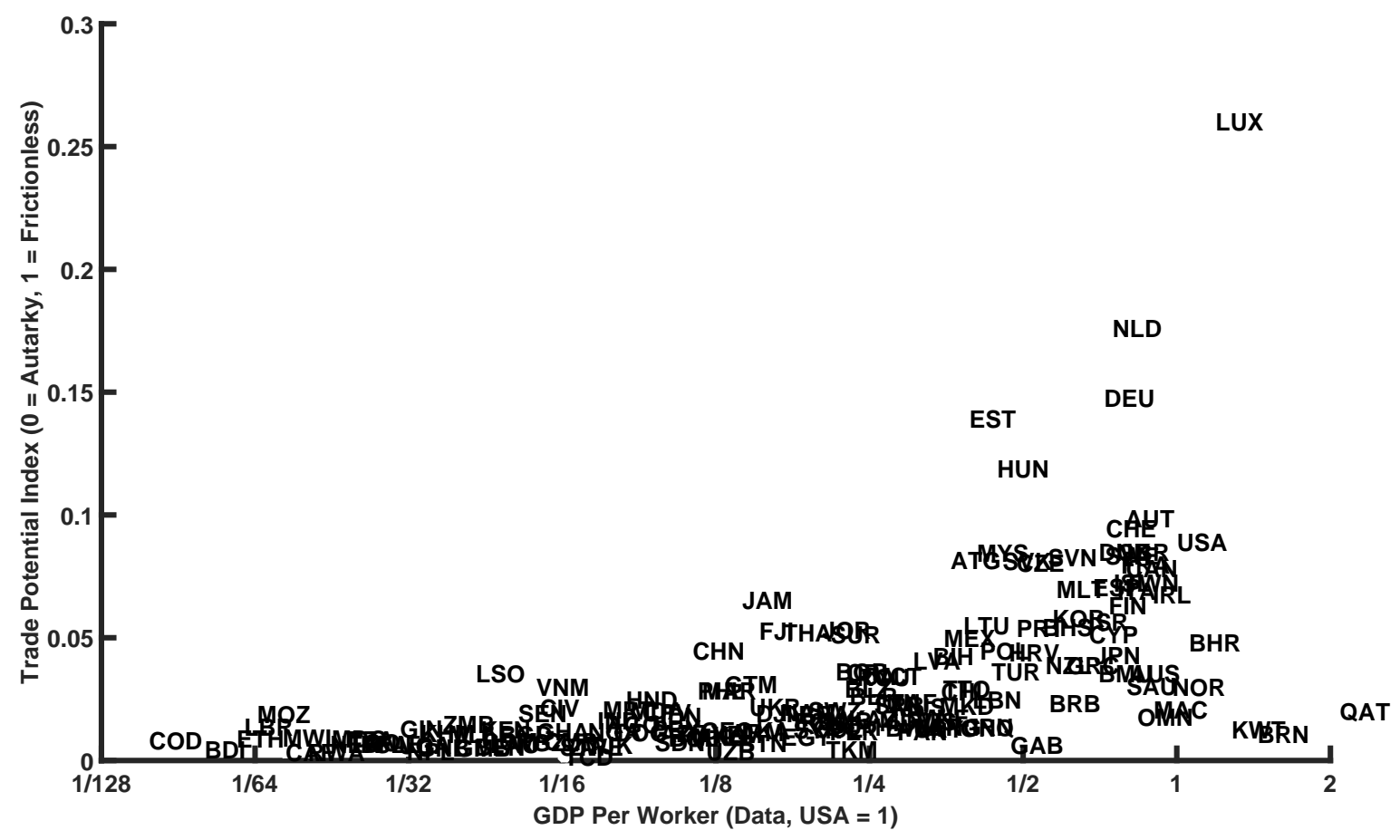

(b) Zoomed In

Figure 2: Trade Potential Index $\Lambda_{i}$ Versus GDP Per Worker 
only 0.03. Or, on average, the world is 97 percent away from the frictionless trade frontier.

Figure 2(b) shows that rich countries are more open compared with poor countries. The correlation between log GDP per worker and our trade potential index is 0.57 . Rich countries are closer to their potential than poor countries. To put this in perspective, the correlation between $\log$ GDP per worker and the welfare cost of autarky is only 0.38 .

The U.S. and Malawi are good examples of this pattern. Autarky income for the U.S. is almost the same as its observed income and the same is true for Malawi. The frictionless-trade income for the U.S. is 1.5 times its observed income but the frictionless-trade income for Malawi is 7.5 times its observed income. The U.S. is not exceptional in the magnitude of its welfare cost of autarky, yet the U.S. is among the top 10 most open countries in the world according to our trade potential index. Our insight is that the low cost of autarky for the U.S. might tempt one to conclude that U.S. is mostly closed, but when compared with its potential, it is very open.

Table 1 illustrates this point further. The second column reports the top 10 most open countries as measured by the welfare cost of autarky. Many of these countries are small, island countries with large trade volumes. The third column reports the top 10 most open countries as measured by our trade potential index. By our metric, many of the most open countries are developed, with reputations for liberal trade policies. Per our discussion above, the important observation is that while these countries might have relatively lower trade volumes, compared with their potential they are very open.

\section{Trade Frictions and Trade Potential}

This section asks a follow-up question: How does our trade potential measure relate to the underlying frictions that impede trade? The difficulty in answering this question is that we must now take an explicit stand on the underlying frictions in order to calibrate or estimate them using the model in Section 2.

\subsection{Calibration}

Calibrating trade models of this type presents a challenge because there are many trade costs and technology parameters to discipline. This is not a challenge in the welfare cost of autarky calculations in (13), which are model consistent yet do not require explicit stands on (potentially) hard-to-infer parameters.

Our objective is to have a parsimonious description of the trade costs and add as little data as necessary to the data used so far. To achieve this objective, we reduce the parameter space such that each country faces only one trade cost, $\tau_{i}$, to import from all other countries. We assume that this one cost succinctly summarizes the trade frictions each country faces. 
Table 2: Calibrated Trade Costs

\begin{tabular}{lcc}
\hline \hline & Mean $\tau$ & Median $\tau$ \\
\hline All countries & 6.99 & 6.59 \\
Rich & 4.92 & 4.64 \\
Poor & 9.06 & 8.44 \\
\hline
\end{tabular}

Note: Rich is the set of countries above the median GDP per worker. Poor is the set below.

To calibrate these trade costs, we use the following procedure. First, we infer the technology parameters using equation (8). Unlike our results in Proposition 2, we must use data on capital stocks and capital shares to invert the technology parameters. Recall that this was not necessary in Proposition 2 as a country's total GDP was a sufficient statistic for the role of endowments.

We use the capital stock measures for the year 2005 from the PWT 8.1. Given the structure in equation (12), we want $\alpha$ to be consistent with the exercises in the development accounting literature. To do so, we set $\alpha$ equal to $1 / 3$. Gollin (2002) provides an argument for setting $\alpha$ equal to $1 / 3$ by calculating labor's share for a wide cross section of countries and finds it to be around $2 / 3$ with no systematic variation across income levels.

We then choose the $\tau \mathrm{s}$ to be such that the model in equilibrium exactly fits each country's observed home trade share. Appendix B describes the algorithm used. This procedure results in the model exactly matching the observed cross-country distribution of GDP per worker and each country's home trade share. This result also implies that the frictionless trade equilibrium of our calibrated economy will be the same as the quantitative results presented in Section 4 .

\subsection{Trade Costs Correlate with the Trade Potential Index}

Table 2 presents statistics summarizing the calibrated trade costs. There are several notable observations. First, the calibrated trade costs are large. The mean and the median trade cost are about 7 and 6.5, respectively. This is not an abnormal result relative to other estimates using trade models with a gravity structure (see, for instance, the discussion in Anderson and van Wincoop (2004) on inferences of trade costs from theories with a gravity structure).

Second, the trade costs are substantially larger for poorer countries. Table 2 illustrates this point by reporting the trade costs for poor countries, which are defined as countries with GDP per worker below the median, while rich countries are those with it above the median. Poor countries in our sample have trade costs almost twice as large as those for rich countries.

The intuition for both these observations lies in Section 4. Relative to the frictionless frontier, 
the observed levels of trade are small. Thus, to reconcile the small trade levels, the model needs large frictions. Moreover, poor countries have a higher trade potential relative to rich countries, so poor countries require even larger frictions to reconcile their relatively larger distance to frictionless trade. The next observation makes this connection between our trade potential index and the trade costs even tighter.

Third, the calibrated trade costs correlate highly with our trade potential index in (21). In fact, they move almost one-for-one with each other. Figure 3 illustrates this by plotting the $\log$ of our trade potential index versus the log of the calibrated trade costs. Countries with a higher trade potential index have lower trade costs and vice versa. The correlation between the trade potential index and the trade cost is -0.94 . This correlation is not spurious or mechanical (for example, trade potential is correlated with GDP as are trade costs and so on). Even after conditioning on income level, the correlation is -0.88 .

In contrast, the calibrated trade costs are only modestly correlated with the welfare cost of autarky with a correlation of -0.48 . Conditional on income, the correlation is only -0.28 . The U.S. illustrates this point well. The U.S. has a low welfare cost of autarky, yet our calibrated trade cost for the U.S. is also small. This incongruence disappears with our trade potential index: The U.S. is one of the most open countries and has one of the lowest trade costs.

These results provide a resolution to some puzzling findings in EK. In their data, Japan appears to be one of the most closed economies with a relatively low import share. But their estimates of bilateral trade frictions imply that Japan is one of the most open countries. In contrast, Greece appears to be a very open economy with a very high import share, yet they estimate Greece to be one of the most closed countries in terms of trade frictions. Our explanation is that Japan and Greece have different trade potentials.

The tight connection between trade costs and the trade potential index is not specific to our calibration procedure. To illustrate this, we compare the trade costs from Simonovska and Waugh (2014) with our trade potential index. Simonovska and Waugh (2014) estimate trade costs using the model-implied gravity equation and bilateral trade data for 119 of our 160 countries for the year 2004. Because their trade costs are bilateral, we average across all import and export pairs for each country to compute one trade cost per country. The correlation between our trade potential index and their average trade cost is high at -0.75 . Because Simonovska and Waugh (2014) use different data and a different estimation procedure, there is no mechanical reason for their trade costs to correlate so strongly with our trade potential index.

Furthermore, average trade costs from Simonovska and Waugh (2014) have very little correlation with a country's home trade share (in their sample or ours). In their sample, the correlation between average trade costs and a country's home trade share is -0.14 . The implication is that the welfare cost of autarky says little about the underlying frictions to trade and that the simple 


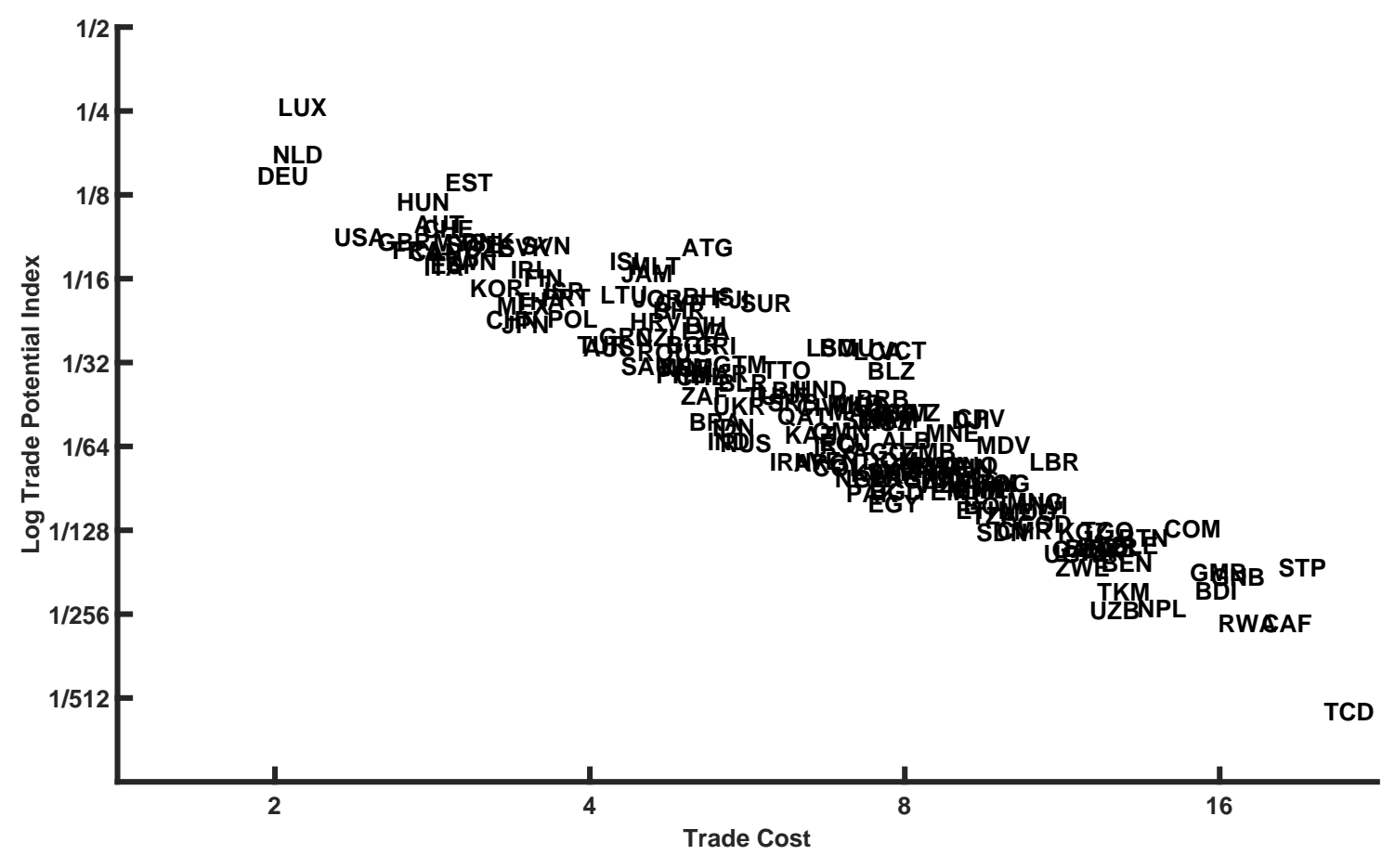

Figure 3: Trade Potential and Trade Costs

statistic in (21) summarizes well the underlying frictions that a country faces (in addition to measuring how open a country is).

\section{Concluding Remarks}

In this paper, we developed a measure of how much a country could potentially gain from trade. This measurement took a simple form and depended only on the country's observed home trade share, its level of GDP, and the trade elasticity.

This measurement provided new insights about which countries are open and which are closed. By traditional measures of openness to trade, such as the volume of trade or the welfare cost of autarky, highly developed economies such as the U.S., the U.K., and Germany look less open than Malta, Iceland, and Suriname. In contrast, our measure takes into account that different countries have different potential gains from trade based on their technology and endowments. And, according to our measure of openness, the U.S., the U.K., and Germany are among the top 10 most open countries.

There are limitations to this exercise. In particular, we derived a closed-form solution to the income in the frictionless trade economy and our trade potential was measured relative to this benchmark. Without the closed-form solution, the simplicity of our measurement would be 
lost. However, its simplicity provides a guide to more nuanced quantitative counterfactual exercises (such as reducing the trade frictions instead of completely eliminating them). Crucini and Kahn (1996), for instance, compute changes in factors of production and output due to observed changes in tariffs instead of due to the limit point of frictionless trade.

A second limitation is that we abstracted from various embellishments of the model, such as non-homothetic preferences as in Fieler (2011) or multisector extensions as in Caliendo and Parro (2015) or Levchenko and Zhang (2011). Extensions in these directions would certainly be useful for future research.

A final limitation is the treatment of capital. Capital was treated as an endowment andsurprisingly—vanished from our measure of openness. The role of capital and labor was taken into account entirely by observed GDP, which appears in our measure of openness. Understanding capital's response in a model where investment is a function of traded goods (e.g., as in Crucini and Kahn (1996) or Mutreja, Ravikumar, and Sposi (2014) ) could be an interesting extension to pursue. 


\section{References}

Alvarez, F., And R. J. LuCAS (2007): "General Equilibrium Analysis of the Eaton-Kortum Model of International Trade," Journal of Monetary Economics, 54(6), 1726-1768.

ANDERSON, J., AND E. VAN Wincoop (2004): “Trade Costs," Journal of Economic Literature, 42(3), 691-751.

ANDERSON, J. E. (1979): "A Theoretical Foundation for the Gravity Equation," American Economic Review, 69(1), 106-16.

Arkolakis, C., A. Costinot, and A. Rodriguez-Clare (2012): “New Trade Models, Same Old Gains?," American Economic Review, 102(1), 94-130.

Bernard, A., J. Eaton, J. B. Jensen, and S. Kortum (2003): "Plants and Productivity in International Trade," American Economic Review, 93(4), 1268-1290.

CAliendo, L., AND F. PARRo (2015): "Estimates of the Trade and Welfare Effects of NAFTA," Review of Economic Studies, 82(1), 1-44.

CASelli, F. (2005): "Accounting for Cross-Country Income Differences," in Handbook of Economic Growth, ed. by P. Aghion, and S. Durlauf, vol. 1. Amsterdam: Elsevier.

CHANEY, T. (2008): “Distorted Gravity: The Intensive and Extensive Margins of International Trade," American Economic Review, 98(4), 1707-1721.

CRUCinI, M. J., AND J. KAHN (1996): “Tariffs and Aggregate Economic Activity: Lessons from the Great Depression," Journal of Monetary Economics, 38(3), 427-467.

EATON, J., AND S. Kortum (2002): “Technology, Geography, and Trade," Econometrica, 70(5), 1741-1779.

Feenstra, R. C., A. Heston, M. P. Timmer, And H. Deng (2004): “Estimating Real Production and Expenditures Across Nations: A Proposal for Improving the Penn World Tables," NBER Working Paper 10866.

FIELER, A. C. (2011): “Nonhomotheticity and Bilateral Trade: Evidence and a Quantitative Explanation," Econometrica, 79(4), 1069-1101.

Finicelli, A., P. Pagano, and M. Sbracia (2013): “Ricardian Selection," Journal of International Economics, 89(1), 96-109.

Gollin, D. (2002): “Getting Income Shares Right," Journal of Political Economy, 110(2), 458-474. 
Hall, R., And C. JONES (1999): “Why Do Some Countries Produce So Much More Output Per Worker Than Others?," Quarterly Journal of Economics, 114(1), 83-116.

Krugman, P. (1980): "Scale Economies, Product Differentiation, and the Pattern of Trade," American Economic Review, 70(5), 950-959.

Levchenko, A. A., AND J. Zhang (2011): “The Evolution of Comparative Advantage: Measurement and Welfare Implications," NBER Working Paper 16806.

Melitz, M. J. (2003): “The Impact of Trade on Intra-Industry Reallocations and Aggregate Industry Productivity," Econometrica, 71(6), 1695-1725.

Mutreja, P., B. Ravikumar, And M. J. Sposi (2014): “Capital Goods Trade and Economic Development," Federal Reserve Bank of St. Louis Working Paper 2014-012A.

SimONOVSKA, I., AND M. E. WAUGH (2014): "The Elasticity of Trade: Estimates and Evidence," Journal of International Economics, 92(1), 34-50.

WAugh, M. E. (2010): “International Trade and Income Differences," American Economic Review, 100(5), 2093-2124. 


\section{Appendix}

\section{A. Trade Potential}

Below, we walk through the derivation of some of the relationships that we exploit. Our goal is to find an expression for each country's trade potential.

First, the balanced trade condition, in general, is

$$
L_{i}\left(w_{i}+r_{i} k_{i}\right)=\sum_{k=1}^{N} L_{k}\left(w_{k}+r_{k} k_{k}\right) \lambda_{k i},
$$

which states that total income in country $i$ must equal the total purchases of $i$ 's goods made by all countries. These country-specific purchases equal the income in country $k$ times the expenditure share that country $k$ spends on goods from country $i$, i.e., $\lambda_{k i}$. Note the right-hand side of (22) includes purchases of country $i$ from itself.

In frictionless trade, all countries purchase the same amount from country $i$. That is, $\lambda_{k i}^{F T}=$ $\lambda_{i i}^{F T}$. Then (22) implies that, in frictionless trade, the home trade share of country $i$ must equal country $i$ 's share in world GDP:

$$
\lambda_{i i}^{F T}=\frac{L_{i}\left(w_{i}^{F T}+r_{i}^{F T} k_{i}\right)}{\sum_{k=1}^{N} L_{k}\left(w_{k}^{F T}+r_{k}^{F T} k_{k}\right)} .
$$

Note that the relevant terms on the right-hand side of (23) can be replaced with real GDP since with frictionless trade the price index is the same in each country. Thus, we have

$$
\lambda_{i i}^{F T}=\frac{L_{i} y_{i}^{\mathrm{FT}}}{\sum_{k=1}^{N} L_{k} y_{k}^{\mathrm{FT}}}=\frac{Y_{i}^{\mathrm{FT}}}{\sum_{k=1}^{N} Y_{k}^{\mathrm{FT}}},
$$

where $Y_{i}^{\mathrm{FT}}$ is country $i^{\prime}$ s total real GDP.

Then, from equation (17) we note that

$$
\left(\frac{Y_{i}}{L_{i}} k_{i}^{-\alpha}\right)^{\theta} \lambda_{i i}=T_{i}=\left(\frac{Y_{i}^{\mathrm{FT}}}{L_{i}} k_{i}^{-\alpha}\right)^{\theta} \lambda_{i i}^{F T} .
$$

Eliminating the common terms and substituting for $\lambda_{i i}^{F T}$ from equation (24), we get

$$
\left(Y_{i}^{\mathrm{FT}}\right)^{\theta} \frac{Y_{i}^{\mathrm{FT}}}{\sum_{k=1}^{N} Y_{k}^{\mathrm{FT}}}=\left(Y_{i}\right)^{\theta} \lambda_{i i} .
$$


Thus,

$$
Y_{i}^{\mathrm{FT}}=\left(\sum_{k=1}^{N} Y_{k}^{\mathrm{FT}}\right)^{\frac{1}{1+\theta}}\left(Y_{i}\right)^{\frac{\theta}{1+\theta}} \lambda_{i i}^{\frac{1}{1+\theta}} .
$$

Summing the left-hand side as well as the right hand side helps us solve for $\sum_{k=1}^{N} Y_{k}^{\mathrm{FT}}$ and arrive at the trade potential in equation (20).

\section{B. Algorithm for Calibrating the Model}

Below we describe the procedure for calibrating the model. Our strategy is to pick one $T$ and one $\tau$ per country to exactly replicate the observed distribution of real income per worker, $y_{i}$, and home trade shares, $\lambda_{i i}$.

We use our development accounting results to recover the $T$ s. So

$$
T_{i}=\left(\frac{y_{i}}{k_{i}^{\alpha}}\right)^{\theta} \lambda_{i i}
$$

This is straightforward.

With the assumption of one trade cost per country, the home trade share is

$$
\lambda_{i i}=\frac{T_{i}\left(r_{i}^{\alpha} w_{i}^{1-\alpha}\right)^{-\theta}}{\sum_{\ell=1}^{N} T_{\ell}\left(\tau_{i} r_{\ell}^{\alpha} w_{\ell}^{1-\alpha}\right)^{-\theta}} .
$$

Notice that we can reexpress the home trade share as

$$
\lambda_{i i}=1-\tau_{i}^{-\theta} \frac{\sum_{\ell \neq i}^{N} T_{\ell}\left(r_{\ell}^{\alpha} w_{\ell}^{1-\alpha}\right)^{-\theta}}{\sum_{\ell=1}^{N} T_{\ell}\left(\tau_{i} r_{\ell}^{\alpha} w_{\ell}^{1-\alpha}\right)^{-\theta}} .
$$

Rearranging equation (30) yields the following relationship between trade costs:

$$
\tau_{i}=\left\{\left(1-\lambda_{i i}\right)\left(\frac{\sum_{\ell=1}^{N} T_{\ell}\left(\tau_{i} r_{\ell}^{\alpha} w_{\ell}^{1-\alpha}\right)^{-\theta}}{\sum_{\ell \neq i}^{N} T_{\ell}\left(r_{\ell}^{\alpha} w_{\ell}^{1-\alpha}\right)^{-\theta}}\right)\right\}^{\frac{-1}{\theta}}
$$

We then use the relationship in (31) to find the vector of trade costs that matches the home trade shares exactly using the following algorithm.

1. Guess a vector of trade costs and compute equilibrium prices ( $r$ and $w$ ) and home trade shares. 
2. Given equilibrium prices, use (31) to generate a new/updated vector of trade costs.

3. Stop if the updated trade costs are close to the previous values. If not, return to Step 1 with the new guess being the updated values. Iterate until convergence.

The benefit of this procedure is that it is faster and more robust than using a nonlinear solver to find the trade costs that best fit home trade shares. Moreover, many different initial guesses always generated the same set of trade costs. 